\title{
Nomadic Contagion and the Performance of Infrastructure in Dale Farm's Post-eviction Scene
}

\author{
Lynne McCarthy
}

The dismantling of an unauthorized Irish Traveller settlement at Dale Farm, Essex, in 2011 showed how nomadic infrastructures are made to disappear. Thereafter, local authorities reconstituted the razed residential foundations of Dale Farm by moulding the disturbed soil of the eviction into 6-foot banks enclosing the boundaries of family plots and with the result of impeding access to those properties. Significantly, the property remained the legal belonging of the Travellers as the Dale Farm dispute was not an issue of trespass but one of planning permission. These banks, termed 'bunding', are used to stop the spread of pollutants from exposed topographies and are a legal Environmental Protection Agency mechanism used for the containment of chemical and toxic waste (EPA 2012). The only other application of 'bunding' beyond industrial waste sites is in nomadic Traveller sites where it is routinely erected to prevent access to their halting areas (Crowley and Kitchin 2007: 137). Filled by storm water, the bund-walled areas of Dale Farm floated open sewage and asbestos, insidiously exposing remaining residents to the contaminants that collected in these enclosed landscapes.

In this chapter I examine bunding as an obstruction infrastructure that discretely conducts infection to Traveller communities while enacting a cultural and environmental racism towards them. Infrastructure performs through a system of organs - quite literally through its sewage and water systems, its ventilation systems, road networks, open spaces and enclosures - to maintain public health or, its opposite, in the case of environmental racism. As I will show, infrastructure is an administrative tool of social control operating through dispersed techniques that produce easily misidentifiable affects. I argue that bunding is representative of a state disposition towards Travellers that obliges them to act with property in ways that are punitive. In addition to the social cleansing routinely experienced by Irish Travellers in evictions, I discuss the putative hygienic use of bunding through 
the paradox of isolating contaminating substances while simultaneously containing Travellers, as distinctive subjects, to these areas. Containment and contamination operate as opposing principles in public health where isolation is considered a remediative public good to the menace of contagion, yet Travellers are paradoxically contained close to polluting substances and put in harm's way. I read bunding as an aesthetic infrastructure (Larkin 2013 and Amin 2014) that reproduces feelings, such as being noxious, as daily affects for Traveller populations. Following thinking on infrastructure as statecraft (Easterling 2014), the aesthetic work of pollution (Douglas [1966] 2003), and pain and its contagions (Scarry 1985), I further argue that the purposeful contamination of halting sites at once attaches Travellers to literal sites of infection while performatively reinforcing metaphors of nomadic populations as contagious.

In October 2011, Basildon District Council's enforced eviction of three hundred Irish Travellers in Dale Farm, Essex, sanctioned by the Royal Courts of Justice, was carried out as a legitimate act of dismantlement. The Irish Traveller residents, once expunged, returned to the verges of Dale Farm in the weeks after the initial eviction and did so because they had not been offered alternative ethnically appropriate accommodation by Basildon District Council. Moreover, Travellers reported that on leaving Dale Farm, their caravans had been attended by police escorts who alternated duties at the boundary of each municipality the Travellers passed (Quarmby 2013 and Interview with the Author 2011). Katharine Quarmby notes that three quarters of the residents returned to the laneway adjoining Dale Farm, known as Oak Lane, with the remainder finding pitches in Cambridgeshire (152). Oak Lane was lawful Traveller property that was exempt from official enforcement notices (Puxon 2011). Residents had 'nowhere else to go' as described in one female Travellers' account of the winter spent on these verges (Interview with the Author 2011).

The land at Dale Farm had been purchased by residents in 2001 after John Major's Conservative government (1992-7) abrogated from the public provision of Travellers sites through the 1994 Criminal Justice Act. This act privatized sites by placing the onus on Travellers to buy and maintain their own private property. Although the legal owners, the Dale Farm Travellers lived on the site as an unauthorized development without planning permission. Irrespective of several planning applications made through the advocacy group, the Irish Traveller Movement in Britain, the residents faced the constant probability of eviction (ITMB 2011). Their applications, like that of the 90 per cent of other Traveller planning applications submitted in the UK, were refused planning permission (Ryder et al. 2011). The circumstances of the Dale Farm Travellers exemplified the circumstances of Travellers across 
the UK who were coerced into private land purchase by the restricted and limited provision of public sites after the passing of the 1994 Criminal Justice Act. Additionally, the strengthened trespass laws in the Criminal Justice Act, which indirectly criminalized the practice of nomadism by making it illegal to stop at customary halting sites, were compounded by the closure of transit sites (temporary halting sites) under the same act. The prospect that the Dale Farm settlement would ever be authorized through retrospective planning was unlikely.

\section{Performing nomadic contagions}

The campaign led by conservative MP Michael Howard and The Sun newspaper in 2005 called 'Stamp on the Camps', detailed by Tyler (2013), was a response to Traveller developments such as Dale Farm. Large settlements of three hundred or more people may have seemed conspicuous and without explanation at the time but in fact arose due to the restrictive legislation of the Criminal Justice Act. A petition was lodged by The Sun to Downing Street outlining three demands: firstly, to prevent and dismantle illegal developments; secondly, to limit retrospective planning permission which many Traveller settlements were dependent upon; and thirdly, to rescind on human rights legislation that apparently gave minority groups more of an advantage in terms of the planning system (Tyler 2013: 136). Notably, residents of Dale Farm suffered the untrammelled prejudice that arose from this campaign when it called for sites to be abolished. At the time, Howard visited the entrance to Dale Farm to make an example of the encampments he wished to see dismantled. The present Conservative administration's (2011-) call to rescind the EU Charter of Human Rights and their policies of 'hostile environments' for immigrants and ethnic minorities (Hill 2017) appears to adhere to Howard's earlier policies in 2005 which betray a particular discrimination towards nomads but are latent to a more generalized form of ethnic discrimination.

Prime Minister David Cameron's (2010-16) response to the Dale Farm eviction that 'those people should go home' (BBC 2011) misunderstood Irish Travellers' historical attachments to nomadism in the UK for over four hundred years and signalled an emerging Conservative hostility to immigrants. Such expulsions, conducted on the basis of ethnic difference, are noted in other times of austerity or crisis in English history when the Irish were expelled from Britain in 1413 under Henry V during a period of surplus labour and as a result of an earlier law in 1349, a year after the Black Death when vagrancy was outlawed (Griffin 2008: 31). The fear of 
contagion presented by movements of people and vagrancy is shown here to be a premodern concern, the legacy of which is still perhaps implicit in everyday British attitudes to Travellers. Polluted landscapes, dirty persons and contagious plagues are culturally regulated phenomena derived from notions that a sacred social order and its opposite, a disorderly profane exist - research distinctively explored by Mary Douglas ([1966] 2003). Over time Travellers have become associated with disorder and dirt through frequent allusions to their placing of rubbish and to their very presence as out of place. Mary Ellen Synon of the Irish Sunday Independent notoriously termed nomadism 'the culture of the sewers' in the mid-1990s and was later found guilty of incitement to hatred (Synon 1996). Douglas suggests that dirt is culturally perceived and a cause of fear precisely because it is something determined to be out of place with the dominant social order and thereby a threat to its stability. Although critiqued for her structuralism, Mary Douglas's thinking is apt in consideration of how contagion, not just in terms of medical materialism but in terms of culture, proliferates. The notion that something out of place poses a threat to in-common cultural production is an insight into the irrational fear and hatred often confronted by Travellers.

Christopher Griffin's anthropological work, Nomads under the Westway (2008) is an empathetic account of how London-based Irish Travellers have been tactically moved on by various city councils. The title refers to a small group of Travellers who consistently struggled with the borough of Kensington and Chelsea during the 1970s, the same borough, who, as I write, are accused by residents of mishandling the catastrophic fire at Grenfell Tower, a social housing high-rise where fire rapidly took hold in the summer of 2017 killing eighty or more people. Local authorities attempting to abrogate from site delivery in the 1970s could apply for an exemption if 'they could prove they had no "suitable" land for the purpose' or that the territory had a 'negligible' number of Travellers (Griffin 2008: 109-110). Such an exemption was granted to Kensington and Chelsea who subsequently evicted their Irish Traveller population. This group of Travellers were eventually resited under the Westways flyover by Hammersmith and Fulham Council (Griffin 2008). However, as Griffin notes the flyover leaked drops of lead onto trailer rooftops and the cramped open spaces of this site, which has been an ongoing source of concern for residents' health.

Placing Traveller populations near polluted sites is a means by which discrimination against them is compounded through associations with dirt and disease. 'Environmental racism', a term describing how the world's ethnic and low-income populations are routinely placed on disinvested real estate close to polluted environments, is a process of 'differentiations in social reproduction' within capitalist accumulation (Katz 2001: 711). 
'Environmental racism' takes place when a 'geographical fix' is required for 'political-ecological problems, such as the siting of toxic waste repositories or the location of noxious industries (often regulated out of wealthier or more privileged locales)', and resulting in the 'social relations that encourage production in one place tapping [for instance,] a migrant workforce reproduced elsewhere' (Katz 2001: 715). In 'The Decline of Nomadism', Greenfields and Smith note such attributions to Traveller property and Travellers themselves derive from processes of 'boundary maintenance' that are upheld through categorisations of 'urban poor/Gypsy' which, give 'recourse to areas of slum housing and to marginal and derelict tracts of land thus reinforcing still further public association of Gypsies and Travellers with dirt and disorder (2013: 3).' In 2009, the Equality and Human Rights Commission (EHRC) reported that 'although conditions vary, many publicly provided sites are of poor quality with sites built on contaminated land, close to motorways, adjoining sewage works, or on other poor quality land' (Cemlyn et al. 2009: 9). Similarly, Griffin's historical tracing of the migrations of Irish Travellers in Britain observes earlier communities in Notting Dale circa 1879 where, according to a historical testimony, nomads were placed in the ugliest place known in the neighbourhood of London, a tract of land torn up for the Brickfield clay, half consisting of fields laid to waste in expectation of the house builder, which lies just outside Shepherd's Bush and Notting Hill' (64).

Representations of Traveller populations are conjoined with metaphors of contagion in the way that a Traveller might stand in as or personify contagion itself. Mary Ellen Synon's phrase, 'culture of the sewers', equates human waste as a stand-in for Travellers and is evocative of terms like 'defecation', 'infection', and 'disease.' These mental concepts of travelling populations as contagious have, perhaps, overworked the metaphor to the point of making it literal. When Traveller populations are geographically located near polluted sites and wastelands, ideas of contagion become literal because such sitings give an impression that Traveller lifestyles are the cause of pollution less than that the siting is symptomatic of their subjection to an environmental racism. At the same time, becoming contagious is a serious risk, if not certainty for Traveller health. Moreover, contagion and its analogues are, as Douglas ([1966] 2003) notes, culturally regulated instruments of this social order, and I argue these are shown to be arbitrated by metaphors that stick to Traveller subjectivities.

Furthermore, these states of threatening contagion lead to practices of containment. Travellers are segregated and self-segregating; they are legally restricted in the places they can reside and temporarily inhabit, and Dale Farm residents' cultural preference was to dwell in extended settlements 
with their kin and removed from mainstream populations. These politically ambiguous detaining and self-detaining practices suggest that containment is a performative and affective ontology for Travellers. Self-imposed and imposed detentions become performative when they train nomadic populations into an acceptance of life on the verges as punitive and restrictive. Travellers isolate themselves from what they see as their discriminatory treatment by sedentary populations only to confine themselves in the very spaces where that discrimination is executed so that it is only they who are witness. These performative situations are composed of oblique interactions as the enactors of evictions silence their addressees by obstructing any possible redress. The performative work in the edict, 'I evict' has an affective implication for its compulsory addressees, in this case a Traveller subjectivity that becomes suspended. Similarly, the affective Traveller ontologies that are at stake, like Ngai's (2005: 1) work on 'ambivalent situations' of 'obstructed agency' (32), are that negative affects become a primary mode of Traveller existence. Such 'ugly feelings' are expressed towards Travellers by producing them as 'racially marked subjects' (95) through states of 'animatedness' that evoke the 'exaggerated expressiveness of the racial stereotype' (94). For Ngai being 'animated' has racialized affects pertaining to notions of emotional excess, surplus or the superfluous, which can line up with 'dramatizing the animation of racialized bodies for political purposes' (98). So too are Irish Travellers racially animated and dramatized through mainstream media and public discourses in the UK. On the back of Channel 4's success with My Big Fat Gypsy Wedding (2011) a second series was advertised across billboards in 2012 as 'Bigger Fatter Gypsier' with this text overlaid by an image of a freckled, red-haired Traveller child, amongst a campaign dominated by other deprecating imagery (Allen 2012). The use of comparative adjectives attested to the fullness of Channel 4's stereotypical animation of Travellers, and this was made all the more unforgivable by foregrounding an identifiable child as a receptor for the types of racialized tones incited by the text. The ad was censored as a result of a complaint made by the Irish Traveller Movement to the Advertising Standards Authority (ITMB 2012: 3). ${ }^{1}$ I now elaborate on how environmental racism is enacted through infrastructure, which in turn fosters a performative relation between Travellers and their property that is obstructive.

\section{Nomadic infrastructure}

The landscape left razed at Dale Farm after the eviction attested to the destitute conditions to which the Travellers returned. Basildon District Council, the 
initiators of the eviction, instructed bailiffs to mount the banks of soil known as 'bunding' and further restricting Traveller use of their own property. These banks encircled and obstructed each plot in the development on a familyby-family basis. The bunding was mounted to the head height of an average adult and posed serious safety risks for the Travellers by cutting off a central collective amenity where laundry was undertaken and increasing the owners' probability of accidents (Quarmby 2013: 115). Fallen signs left by the council declared the land uneven and unsuitable for children's play when ironically, the topography had been deliberately arranged as such by the council. These were the ways that Travellers were obstructed from undertaking their daily routines by the bunding at Dale Farm, while emphasizing racialized attitudes in the policing of Traveller property.

The local council's use of the term 'bunding' has its provenance in industrial construction where it is used as a description of a defence wall that contains 'potentially polluting substances', for instance (EPA 2012). In industrial practices and in examples given in the manual of the Environmental Protection Agency (EPA), a bund wall is deployed as a secondary defence mechanism and is typically built as a fail-safe around a structure that produces hazardous substances, such as bulk chemical stores (EPA 2012). It could be argued on the council's behalf that potentially hazardous pollutants, such as sewage pipes, could burst in the course of the eviction or that because the site had previously been used as brown belt for the dismantlement of cars, upturning the soil would inevitably expose pollutants. Based on photographic evidence I recorded after the eviction, it is clear that sewage pipes were left exposed and that raw sewage ran along the channels where bunding had been constructed in parallel (see Figure 9.1; EPA 2012). It suggested that the rationale for the construction of the bunding, which was to prevent contamination, was left unfulfilled by the council. Many of the hard structures including static homes had been removed by the Travellers for safety prior to the eviction, reducing the building materials that would normally produce hazardous waste in demolition work. There were valid grounds for Basildon District Council to make an effort to restrict the escape of pollutants from Dale Farm, but this effort was not completed to a standard where the pollutants were actually conducted safely away from the site and where the topography was returned to a protected state. The significance of this is that Basildon District Council had argued in the courts against the illegal use of land at Dale Farm for residential (brown belt) purposes rather than as its intended use as undeveloped green belt land.

In industrial demolition practices, it is usual to capture storm water that can carry pollutants by creating conduits or laying down a cover of peat that retains the water and, thus, pollutants (EPA 2012). In effect, the bunding did 


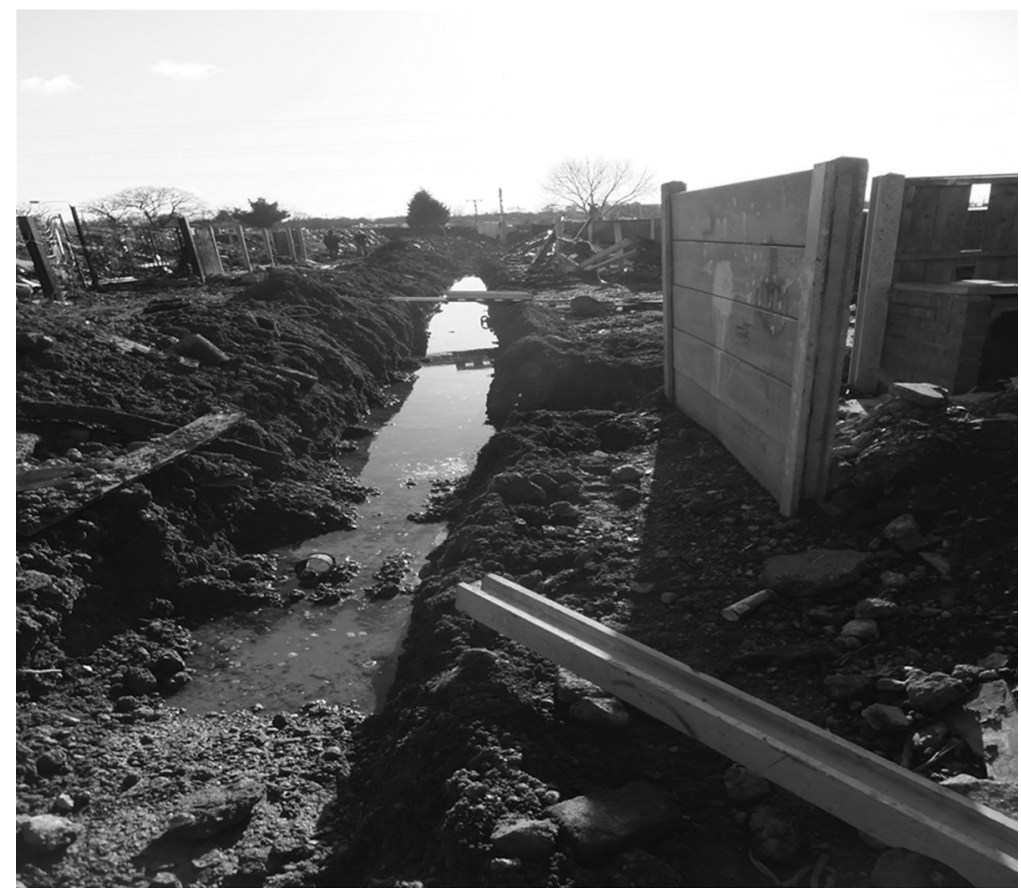

Figure 9.1 Open sewage flows between the Bund Walls at Dale Farm, 2012. Photo by Lynne McCarthy.

little to reduce the problem of pollution and BDC palpably put the owners, who had the right to use the land for greenbelt purposes, at health risk. The Travellers were also astonished that the very subject of the eviction reverting the land to green belt usage - had not been followed through by the council (Puxon interview 2011).

I consider bunding as a form of municipal infrastructure that was implemented on an ad hoc basis by Basildon District Council. It is, I argue, an infrastructure that detains livelihoods and chronically limits the activities and social reproduction of Dale Farm Travellers. Typically, infrastructure is designed and implemented by states to further their goals of networks of communication, commerce and social reproduction, but infrastructure deployed as a form of obstruction shows how a state or municipality can wield geographical technologies to discontinue aspects of social life. In Seeing like a State, James C. Scott has questioned state schemes like planning systems that appear at face value to enact empirical and logistical programmes of state maintenance but are the utilitarian means through which social ordering, 
population management or social planning occurs and whose legibility is necessitated through 'state simplifications' (1998: 310). The imposition of formal order on local informal process can have disastrous consequences, like the famines resulting from Soviet Collectivisation or China's Great Leap Forward (310), which Scott notes killed local technical knowledge, initiative and 'metis' (309-320). Planning scholar Keller Easterling sees planning as 'a battery of legal restrictions constructed to disenfranchise a population through its housing or its land' (2003: 88-89). Similar strategies of obstruction infrastructure were deployed in Ireland to abolish nomadism in 1964 when the National Council on Itinerancy pursued a settlement programme for Travellers (Wickstrom 2012). Since then local authorities, who feared the permanent migration of Travellers to their areas, undertook an 'unofficial policy' of 'evicting its non-indigenous Travellers and forcing its indigenous Traveller population into large settlements (often without services) in remote areas and placing boulders and digging ditches on Travellers' traditional camping sites' (Crowley 2005: 142-144). In Maurya Wickstrom's work on Irish Travellers' theatre practices in Ireland, she notes a bureaucratic practice of building walls around Travellers' encampments as a form of containment (2012: 157). In open spaces across Ireland and England councils deploy several techniques, such as height-adjustable barriers that are electronically activated to rise as a barricade and prevent Traveller incursion onto public space, as the need arises. As a result of obstruction infrastructure Travellers are either perpetually in movement or have been hegemonically settled in a small number of authorized and unauthorized pitches.

Keller Easterling describes in more detail how infrastructural space has become so much more than just the substructure of a city but a powerful 'medium of information' that 'resides in invisible, powerful activities that determine how objects and content are organized and circulated' (2014: 13). She has termed this phenomenon 'extrastatecraft' because it captures the 'often undisclosed activities outside of, in addition to, and sometimes even in partnership with statecraft' (15). Her central argument is that the state and its undertakings are often camouflaged through infrastructure and its systems and that infrastructures can become an enactor and 'instrument of militarism, liberalism, or universal rationalisation' (17). Infrastructural techniques, in particular free zoning (where vast tracts of urban landscapes are converted into uber-cities and have their own transnational laws and immunity to national jurisdiction, for example, King Abdullah Economic City in Saudi and Songdo City in South Korea, to name but a few), are manifest 'concentrations of authoritarian power' (22). Infrastructural forms are conduits of power that have deflected and immunized themselves to critiques of neo-liberalism. She also describes 
how infrastructures can direct, redirect and control systems of movement whether these are physical, financial or technological, and therefore, their 'topologies are also markers of political disposition insofar as they highlight the ways in which the authorities circulate or concentrate information' (77). The political disposition of infrastructure is evident in Basildon District Council's construction of bunding as it made a clear statement that Traveller access to their land through the means of their own cultural preference was prohibited. Political information is, therefore, transmitted through the topologies created by bunding and, additionally, these politics are reinforced by the semiotic connotations implied by BDC's use of the term 'bunding' rather than, say, the term 'dyke', the former distinctly conveying a sense of the contagious. Bunding is not typically applied to domestic demolitions; rather it is used within industrial and pharmaceutical construction. Linking Travellers' domestic space to a term that is connotative of hazardous waste shows another instance of how the metaphorical association of Travellers with toxicity and contagion is literally performed through bureaucratic processes and terminology. More significantly, by embedding the logic of 'contamination' as a rationality of governance over the Travellers, the council (and by default, the state) shows a regard for nomads as subnationals with the potential to pollute or infect the sedentarist population. I maintain that infrastructure and infrastructural terminology is applied in these contexts to disguise state intolerance of nomadic populations.

Covertly deployed infrastructural techniques inhibited nomadic movement at Dale Farm and ensured that a charge of direct discrimination could not be levelled against Basildon District Council. Yet, by impeding the use rights of the Travellers, an indirect discrimination was perpetrated through property relations. The council's discriminatory acts were carried out through dissimulation; the bunding has since become a part of the natural history of Dale Farm, where grass and weeds have taken root (see Figure 9.1). Typical bunding is composed of man-made materials not unlike how the foundations of a building might appear when initially laid out. This technique differed at Dale Farm because the bunding was constructed of soil making it evade the appearance of its actual purpose as a blockade. Instead, it appeared more as an incidental feature of the landscape and part of its natural history, particularly when overgrown with grass half a year later. It is in such ways that I suggest 'state violence' is exercised through objective law, not necessarily as palpable acts of lethal or brutal violence but as bureaucratic tactics that remain undeclared and that make life untenable (Benjamin 1978: 300). Neither the boulders nor the bunding is inscribed with the words 'keep travellers out', yet by implanting such infrastructure the sentiment that is carried out performs a type of state racism that permits only some groups 
access to property but not to others. The objective law determined that the Travellers had misused the land at Dale Farm, yet it is difficult to conceive how Basildon District Council has not equally misused objective law to stealthily enact the continued dispersal of the Travellers (Figure 9.2).

The statecraft elucidated by Scott as systems of legibility designed for the simplified management of population can also be considered in its inverse and closer to Easterling's interpretation, as deliberately illegible. The dissimulation brought about by the undisclosed function of the infrastructure at Dale Farm evinced how statecraft is reliant on stagecraft. In its theatrical context, stagecraft refers to the practical knowledge and skill required to produce a mise-en-scène by dramatizing physical space, revealing and concealing the mechanics of staging. Representations are defined through the technical visual precisions of stagecraft, emerging as this character, that community, that time or these geographies. Not all stagecraft is constructed to be duplicitous for in as much as it is historically read as pretence, it can also be illuminating. It is pertinent that the cultural meanings and ideological applications of stagecraft at any given time are distinguished. In this instance, the fact of concealing the purpose of the bunding, and its very theatrical implementation onto the Dale Farm landscape as a framing of Traveller property, attests to the critical function of stagecraft for the state proliferation of its own agendas. State agendas and stagings of democracy have everything to do with the framing of representations and in deciding which populations are to be made visible as part of that representational politics.

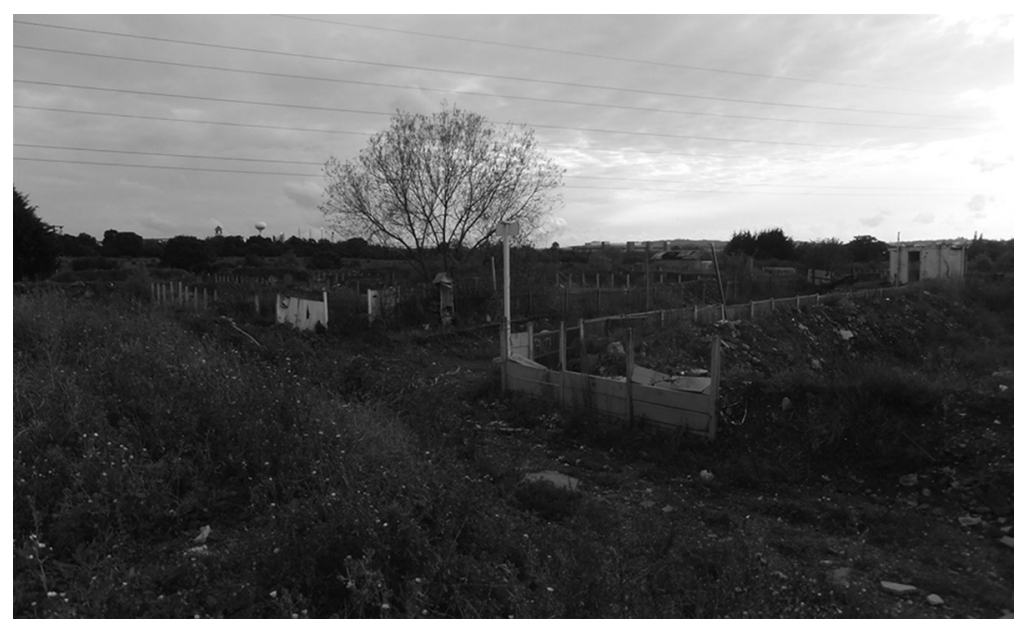

Figure 9.2 Dale Farm overgrowth, 2012. Photo by Lynne McCarthy. 
The moulded landscape at Dale Farm suggests that not only are nomads animated as a racialized group but that their infrastructure is animated as a state response to their mobilities. Easterling's identification of the political dispositions contained in the surfaces of infrastructures is considered further here as attitudes that are animated through infrastructural form, including their theatrically covert dispositions. Bureaucracy is perceived by Travellers through infrastructures that generate negatively experienced affects. 'Tones' are set by the state in their shaping of Travellers' infrastructures inscribing attitudes that are a 'dialectic of subjective and objective feelings that our aesthetic encounters inevitably produce' (Ngai 2005: 30). Thereby, the state constructs Travellers' dispositions to infrastructure in as much as its own disposition to Travellers is communicated through its infrastructure. While on the road or in situ, nomads encounter sceneries that are composed deliberately of obstructive materials that, conversely, within an alternative sedentarist scene-scape, may appear as accidentally discarded material. Boulders and mounds of earth appear commonly to Travellers as obvious techniques of obstruction, but to sedentarists who make different use of spaces, these materials make little impact on their daily undertakings. The point that recent scholarship has posed around the visibility or invisibility of infrastructure, and to which I turn my attention, is 'not to assert one or another status as an inherent condition of infrastructures but to examine how (in)visibility is mobilized and why' (Larkin 2013: 336).

If infrastructures are the system of objects that 'undergird societies' they also 'generate the ambient environment of everyday life' (Larkin 2013: 326). In this regard, rather than analysing the declared function of infrastructure, I examine the undeclared affective and ambient indiscretions and repercussions of infrastructures' forms. Discussing the poetics of infrastructure, Brian Larkin proposes that infrastructures are 'concrete semiotic and aesthetic vehicles oriented to addressees' (2013: 326). Infrastructures become poetic when organized according to the 'material quality of the signifier' rather than its 'referential meaning' (329). Larkin's argument about infrastructures is founded on the 'palpability of the sign' and how considering infrastructure in light of the poetic means 'form is loosened from technical function' (335). The state can make you feel discretely the meaning of its infrastructure through its forms or feel meanings that are obscured by their technical function. These are feelings about the state and the state of things at quite a literal level but are affective in that their source is often difficult to identify. As a way of feeling the state, infrastructure is an apparatus through which social ordering is exercised via objects and at an arm's length from recognizable power relations. These power relations are performed discretely through a logic that 'disavows itself, seeking to organise populations and territories through 
technological domains that seem far removed from political institutions' (Larkin 328).

Nomadic infrastructure therefore has a duplicitous means of representing itself by making it difficult for the Travellers not to take the bunding and the boulders as social facts that cannot be overcome. The effects of obstruction infrastructure become affectively embodied for Travellers in ways similar to residents of the Brazilian favelas where:

Hyper-visible and constantly evolving infrastructural developments make the atmosphere of place that forms the precognitive of mental, sensory and affective dispositions: the resident's experience of living in the settlement, their feelings and obligation towards each other, their attachment and responsibility towards shared public spaces, their expectations from the commons (which, range from environmental disregard and cohabitation with the makeshift to hyper cleanliness within the private compound and participating in improving communal spaces). (Amin 2014: 146)

Physical obstruction to resources, amenities, communities and kin is accompanied by the negative affects of incommodious infrastructures that bear implications for the performative reproduction of nomads in the UK. Just as Ngai understands tone to be a dialectic between subject and object, a performative relation between subject and object can be elaborated as the uses that occur, are imposed, encouraged, curtailed between people and their property. Observing and living with the bunding produced a felt condition for the Travellers that registered in despair and was also reflected and felt through illnesses. In January 2012, the United Nations unofficially gathered information for a report on the aftermath of the Dale Farm eviction and the living conditions of Travellers. When UN representatives attended the Dale Farm site, I worked with Dale Farm Solidarity to collect data on the residents' health; photographed evidence of burst sewage and water pipes from the site; and took descriptions of the long-term illnesses of the elderly and young who were without amenities, such as electricity, water and sanitation. Being in the vicinity of the bunding caused health problems for the Travellers, one of whom showed me how her hands had become swollen and infected from the open sewage - she assumed - and, although her hands were not violently maimed, her use of them to undertake daily activities, such as looking after her children, was diminished. Strikingly, this geographically enforced behaviour and relationship to her property depleted parts of her personhood by, firstly, obligating her to reroute and adjust her typical care regimes, and secondly, by invasively and infectiously putting her body in the way of harm. 
I argue that the performative relations imposed between her and her property were organized to detain nomadic social reproduction.

Material feelings of illness that disrupt regular activity show how people are affected by infrastructure, how it is given priority over public health, and how it shapes the affects of users, or as the geographer Ash Amin puts it, "how the human is imagined as adjunct to the material' (2014: 137). Scarry notably argued that a 'language of agency' (1985: 15) is given over to the inflictor of pain: 'the feeling of pain entails the feeling of being acted upon, and the person may either express this in terms of the world acting on [her] ("It feels like a knife ...") or, in terms of [her] own body acting on [her] ("It feels like the bones are cutting through")'(16). Therefore, the weakening of personhood through the weakening of agency is a plausible factor in understanding the pain of the female resident at Dale Farm. The source of pain in war is legible to Scarry through instruments of torture, and these explicitly violent situations are to her the presentations of 'fictive power' (58). Conversely, 'non-political contexts of pain' (31) are those relating to disease, old age and auto-degenerative illnesses, but I have shown here that pain caused through infection can also be deliberate at worst, neglectful at best and definitely political, including but not limited to sites of chemical warfare. Moreover, Scarry locates the sensory fabric of pain as the only state that has no object; for example and in contrast, to hear is to hear another object; to feel hunger is to be hungry for an object (1985: 161-162). Pain has no external object but is a type of sense perception that is folded back onto the subject. When pain's external location is imagined as diffuse, ambient and unattached, for instance, the object of 'torture' at Dale Farm is not immediately present, then, I argue that in searching for the location of an object that bears responsibility for pain - no one owns the microbe - the political cause of pain is often less evident. Unlike the searing violence of war, the daily endurance of pain as an irritant that vitiates life is the subject that is taken up by Lauren Berlant as a 'slow death' and a 'physical wearing out of a population in a way that points to its deterioration as a defining condition of its experience and historical existence' (Berlant 2011: 95). Reading the bunding as a type of reservoir for infection, it then becomes intelligible as an object that contributed to illness.

\section{Conclusion}

I have argued that infrastructure can obfuscate human power and responsibility by performing its functions in ways that appear natural (naturally occurring mounds or boulders) and by pursuing a type of purposeful aesthetics that seem to appear accidentally and are normatively 
perceived as benign. I propose that infrastructures must be read in terms of their undeclared tactical purposes by demonstrating where they are used to obstruct populations by performing an environmental racism. Whether through negligence or intent, the effect of having a population feel pain is also an effective way to communicate to them how their agency is actively being weakened. In choosing infrastructure as an object of critical focus here, it has been possible to map its relationship to contagion and social reproduction through aesthetic and performative theories. This has shown that infrastructure is obstructive and that it acts as a conduit to diffuse information and affects to populations, which in turn rise to consciousness, not just as generalized feelings but as pain. This pain is a negative affect or 'ugly feeling' that diminishes the performative possibilities and social reproduction of nomads in the UK. Travellers perceive bunding and other materials as obvious techniques of obstruction that detain life and vitiate against their social reproduction. The containment of Travellers around sites of pollution has implications for municipal and state agendas in the UK who seem tacitly unconcerned that nomadic populations are disallowed from performing their own dispositions to the social but just as significantly, are deteriorating under the performative and biological affects of an obstructive infrastructure.

\section{Note}

1 'The EHRC said, in relation to equality of opportunity, Gypsy and Traveller ethnic groups in Great Britain suffered substantial disadvantage in life chances including in health, education, employment, housing and participation in the community. They said media reporting and portrayal could have a significant impact in shaping public perceptions of Gypsies and Travellers. They said their research had found that the role of the media was a key area in the perpetuation of misunderstanding and that stereotypical images and sensational reporting frequently promoted fear and hatred in local populations. They said such problems were magnified by the absence of countervailing positive images' (ITMB 2012: 3).

\section{References}

Allen, E. (2012) “Bigger. Fatter. Gypsier” Advertising Campaign Used by Channel 4 for Its Wedding Series Is Branded "Racist”, Daily Mail. London: 29 May. Amin, A. (2014), 'Lively Infrastructure', Theory, Culture \{®\} Society, 31 (7-8): 137-161. 
Anon. (2004), Meadowlands Eviction 2004 (Pt 2). Available online: https://www. youtube.com/watch?v=_M4ovSUS86Y (accessed 17 January 2016).

Anonymous Women of Dale Farm (2011), Interview With the Author. Dale Farm, Essex, December: 18. Available online: https://soildepositions. wordpress.com/.

BBC News Essex (2011), 'PM Backs Eviction of Travellers at Dale Farm', September: 7. Available online: http://www.bbc.co.uk/news/uk-englandessex-14828148 (accessed 26 November 2012).

Benjamin, W. (1978), Reflections: Essays, Aphorisms, Autobiographical Writings, New York: Harcourt Brace Jovanovich.

Berlant, L. (2011), Cruel Optimism, Durham: Duke University Press.

Cemlyn, S., M. Greenfields, S. Burnett, Z. Matthews, and C. Whitwell (2009), 'Inequalities Experienced by Gypsy and Traveller Communities: A Review', Bristol. Available online: http://www.equalityhumanrights.com/uploaded_ files/research/12inequalities_experienced_by_gypsy_and_traveller_ communities_a_review.pdf (accessed 22 November 2012).

Crowley, U. (2005), 'Liberal Rule through Nonliberal Means: The Attempted Settlement of Irish Travellers (1955-1975)', Irish Geography, 38 (2): 128-150.

Crowley, U., and R. Kitchin (2007), 'Paradoxical Spaces of Traveller Citizenship in Contemporary Ireland', Irish Geography, 40 (2): 128-145.

Douglas, M. ([1966] 2003), Purity and Danger: an analysis of concept of pollution and taboo, London; New York: Routledge.

Easterling, K. (2003), 'Subtraction', Perspecta, 34: 80-90.

Easterling, K. (2014), Extrastatecraft: The Power of Infrastructure Space, London: Verso Books.

Environment Protection Agency (2012), Working at Construction and Demolition Sites: PPG6 (Pollution Prevention Guidelines), Bristol: EPA. Available online: https:/www.gov.uk/government/uploads/system/uploads/attachment_data/ file/485215/pmho0412bwfe-e-e.pdf (accessed 24 April 2015).

Environmental Protection Agency (n.d.), 'Large Scale Residential Demolition', London. Available online: https://www.epa.gov/large-scale-residentialdemolition/managing-stormwater-and-dust-demolition-sites. (accessed 24 April 2015 and 13 June 2012).

Greenfields, M., and D. Smith (2013), 'Decline of Nomadism: Enforced Settlement and Urban/Gypsy Traveller Camps in London and Its Environs', paper presented to Research Committee 21: Sociology of Urban and Regional Development, Resourceful Cities Conference, International Sociology Association, Berlin.

Griffin, C. (2008). Nomads under the Westway: Irish Travellers, Gypsies and other Traders in West London, Hatfield: University of Hertfordshire Press.

Hill, A. (2017), “Hostile Environment”: The Hardline Home Office Policy Tearing Families Apart', Guardian, 28 November.

Irish Traveller Movement in Britain (2011), 'Dale Farm: Basildon Council's Eviction of a Traveller Community'. Available online: http://irishtraveller.org. uk/wp-content/uploads/2011/09/12.09.11-21.pdf (accessed 13 June 2012). 
Irish Traveller Movement in Britain (2012), Submission by the Irish Traveller Movement in Britain to the Society of Editors Code Committee Consultation, London. Available online: http://www.travellermovement.org.uk/wpcontent/uploads/2015/09/ITMB-submission-to-the-PCC-Code-Committeeconsultation-final.pdf ( accessed 13 October 2015).

Katz, C. (2001), 'Vagabond Capitalism and the Necessity of Social Reproduction', Antipode, 33 (4): 709-728.

Larkin, B. (2013), 'The Politics and Poetics of Infrastructure', Annual Review of Anthropology, 42 (1): 327-343.

Ngai, S. (2005), Ugly Feelings, Cambridge, MA: Harvard University Press.

Puxon, G. (2011-2012), Interviews with the Author, Dale Farm, Essex, October 2011 - March 2012.

Quarmby, K. (2013), No Place to Call Home: Inside the Real Lives of Gypsies and Travellers, London: Oneworld.

Ryder, A., T. Acton, S. Alexander, P. Cemelyn, S. Van Cleemput, J. Richardson, and D. Smith (2011), 'A Big or Divided Society? Final Recommendations and Report of the Panel Review into the Coalition Policy on Gypsies and Travellers', Wales: Travellers Aid Trust.

Scarry, E. (1985), The Body in Pain: The Making and Unmaking of the World, New York: Oxford University Press.

Scott, J. (1998), Seeing Like a State: How Certain Schemes to Improve the Human Condition Have Failed, New Haven, CT: Yale University Press.

Synon, M. (1996), 'Time to Get Tough on Tinker Terror Culture', Sunday Independent, 28 January. Available online: http://www.indymedia.ie/ article $/ 63540$ ? condense_comments=true\&userlanguage $=$ ga\&save_ prefs $=$ true (accessed 9 October 2016).

Tyler, I. (2013), Revolting Subjects: Social Abjection and Resistance in Neoliberal Britain, London: Zed Books Ltd.

Wickstrom, M. (2012), Performance in the Blockades of Neoliberalism: Thinking the Political Anew, New York: Palgrave Macmillan. 